\title{
Collective effectiveness in the $X V$ de France: selections and time matter
}

ADRIEN SEDEAUD ${ }^{1,2}$, GUILLAUME SAULIERE ${ }^{1,2}$, LAURIE-ANNE MARQUET ${ }^{3,4}$, SCOTT DEL VECCHIO ${ }^{1,2}$, AVNER BAR-HEN ${ }^{5}$ \& JEAN-FRANCOIS TOUSSAINT ${ }^{1,2,6}$

${ }^{1}$ IRMES, Institut de Recherche bioMédicale et d'Epidémiologie du Sport, INSEP, Paris, France.

${ }^{2}$ Université Paris-Sud Orsay, Ile-de-France, France.

${ }^{3}$ Laboratoire Sport, Expertise et Performance, INSEP, Paris, France.

${ }^{4}$ Laboratoire Motricité Humaine, Education, Sport, Santé, Université Nice Sophia-Antipolis, Nice, France.

${ }^{5}$ MAP5, UFR de Mathématiques et Informatique, Université Paris Descartes, Paris, France.

${ }^{6}$ CIMS, Paris, France. 


\section{Abstract}

The aim of this study was to quantify the impact of selections and shared selections in the rugby union. Players' names, positions, and number of selections were collected for all XV de France's games (1906-2014). Every team's percentage of turnovers (i.e renewal of workforce) was calculated for backs and forwards. During the 1987-2014 period, all second row forwards (locks), halfbacks, and centres' shared selections (number of times when two players have competed together) were recreated. The Best vs Rest method was applied to these remodelled dyads. They were analyzed and compared with surrounding teammates as well as opponents. Head coaches similarly change their workforce for upcoming matches after winning or losing (around 30\%), but losing teams renew significantly more positions in their line-ups. The recreated halfbacks, locks, and centres reveal a common pattern. Whether victorious or not, the "renewed couples"” victory percentage will congregate toward the XV de France's victory percentage. For all the best recreated couples, the cumulated number of selections for forwards' is always higher than the ones part of less efficient teams: $231.3 \pm 80$ vs $212.9 \pm 91$ selections for locks' teammates (ES small, possibly positive, 54.8\%). In best recreated couples, number 8's are significantly more experienced than their counterparts in less efficient pairs (ES small, likely positive, 76.3\%). The XV de France's collective effectiveness relies on a balance between stability and turnovers, which allows the building of specific position interactions and builds on experimented forwards packs. Selections and shared selections are serious collective performance parameters associated with performance.

Keywords: Rugby union, collective performance, shared selections, sharing experience, teamwork 


\section{Introduction}

Rugby performance depends on energy resources, physical qualities such as strength, speed and power (Cunniffe, Proctor, Baker, \& Davies, 2009; Lacome, Piscione, Hager, \& Bourdin, 2014; Mellalieu, Trewartha, \& Stokes, 2008) as well as technical and tactical skills that work together to bring out team effectiveness. The plurality of these parameters continues to benefit the collective effectiveness with success (i.e the ability to play well together), which is usually assessed with experience. In rugby, experience is a performance indicator that has been studied and used through different approaches. For example, in rugby union and league, performance requires an efficient tackling ability (Gabbett, 2005, 2008); especially with the increased number of tackles and consequently rucks in modern rugby (Eaves \& Hughes, 2003; Quarrie \& Hopkins, 2007). Regarding tackling, a greater playing experience is associated with a better tackling technique (Gabbett \& Ryan, 2009). This link is stronger for athletes who have played more than 150 games at a higher level than the less experienced ones (Gabbett \& Ryan, 2009). This outcome is in accordance with the considerable practice required for improvements in tackling performance (Gabbett \& Ryan, 2009). This important practice time is needed not only for an individual player, but for the team's cohesiveness as well. It is likely that the collective effectiveness responds in a similar way. Indeed, collective experience gathered from previous Rugby World Cups (RWC) has been shown to be a performance factor for forwards (Sedeaud et al., 2012). It was shown that, the more teams won RWC games, the more their forwards shared previous RWC games (Sedeaud et al., 2012). These findings are consistent with previous studies which have found that international players may be selected because of greater skill and experience (Smart, Hopkins, \& Gill, 2013). Another parameter affected by experience is ball-carrying technique while sprinting. Indeed, the more experienced players sprint faster with the ball under one arm and in both 
hands than their less experienced counterparts, whereas experienced and novice players do not differ between their sprint time while running without the ball (Walsh, Young, Hill, Kittredge, \& Horn, 2007). However, most studies assess individual experience by the number of games played or other cumulated athletes characteristics, but rarely in a collective way (Shearer, 2015). Nonetheless, team cohesion, confidence, and collective efficacy are also linked to performance (Heuzé, Raimbault, \& Fontayne, 2006; Stajkovic, Lee, \& Nyberg, 2009). Players involved in a larger number of games do not only have better individual results, but are also considered more efficient and more involved in building group cohesiveness and team performance (Fransen et al., 2014; Heuzé et al., 2006; Leo, Sanchez-Miguel, Sanchez-Oliva, Amado, \& Garcia-Calvo, 2013). These studies focused on interviews with players concerning their perception of their own actions, their teammates' actions, and their own impact on the group's performance. However, it was rarely done in a systematic view of shared comprehension or with a multiyear scope. Duch et al (Duch, Waitzman, \& Amaral, 2010) quantified the impact of team members on the performance using methods inspired by social network analysis. Their approach was based on the concept that the composition of teams determines their odds of success (Guimerà, Uzzi, Spiro, \& Amaral, 2005; Wuchty, Jones, \& Uzzi, 2007), especially the players' interplay contributions. In rugby teams, cohesion dimensions make up a significant proportion of the variance in the collective efficacy scores (Kozub \& McDonnell, 2000). Interplay between teammates is crucial in collective sports, especially with the growing importance of the set piece (i.e scrum, line-out) in modern games. In this context, turnovers have progressively become more decisive due to defences being disorganized. In this case, the ability to read and act on opportunities together is critical to create overlap. Throughout all phases of play, rugby is the result of collective interactions, either in defence (placement, interaction, tackles, and support during rucks, forage, mauls...) or in offense (placement, runs, lures, fixing, support, timing...). Game experience has been 
linked to performance and success in rugby union, but it has most often been recorded individually or by summing individual performances (Shearer, 2015). Collective effectiveness as a synergic construction (through shared playing time) has not been analyzed over long periods of time. The purpose of this study was to quantify the impact of selections and shared selections on the game's result.

\section{Methods}

Data collection

Individual characteristics (name, position, starters or substitutes, date of first selection, selection during a match) for each international game were collected from the first $X V$ de France official match (January $1^{\text {st }}$ 1906) to the final match of the 2014 Six Nations tournament. All games played by the $X V$ de France were collected, including the date, opponent, score, match venue, type of match: test match, V then VI Nations, World Cup

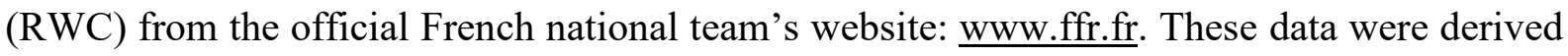
from the longitudinal follow-up of players, with measurements done by $X V$ de France's team physician. Since 1906, the analysis includes 702 games detailed in 11,832 international selections for 1,054 different rugby players.

Over the entire period (108 years), mean player selections were analyzed by match result. Specific analysis was conducted during the 1987-2014 period, reflecting the arrival of the RWC and professional rugby (since 1995).

During this period, the percentage of turnovers (i.e renewal of workforce) by team (declined in forwards and backs) was calculated in function of game results (win or loss). 
In order to identify success factors for the best second row forwards (locks), halfbacks and centres during the 1987-2014 period, all shared selections (as starters) for each dyads were computed game by game. Shared selection represents the number of times when two players have already competed together. For locks, halfbacks, and centres, whose percentages of never renewed players after a loss or a win, which were significantly higher than their counterparts, we redrew all the historical shared selections as a "couple" based upon the game results. A threshold of 4 games shared by couples was set for historical recreated shared selections. In order to compare locks, centres, and halfbacks, two groups were developed: best and rest. The "best vs rest" method divided the previous groups in two by the median of the percentage of victory (percentage derived at the end of the dyads" "career"). The "best" group represents dyads with the highest percentage of victory (above the median), whereas the "rest" depicts couples with a lower percentage (below the median).

Relative to these best and rest recreated halfbacks, locks, and centres, an analysis of their opponents and the numbers of selections by the players who make up the teams are proportionally drawn. All 15 players forming teams surrounding halfbacks, centres and locks are recreated by circles (where the diameter is proportional to the number of mean selections by position), which are drawn on a rugby field.

Statistical analyses

Mean selections by player for victories versus defeats, "best" against "rest" groups comparisons, and percentages of turnovers were compared by Student's t tests. The Effect sizes (ES) were assessed with magnitude-based inferential approach, using standardisation to define magnitude thresholds. ES were classified as trivial $(<0.2)$, small $(>0.2-0.6)$, moderate 
(>0.6-1.2), large (>1.2-2.0) and very large (>2.0-4.0) (Batterham \& Hopkins, 2006; Winter, Abt, \& Nevill, 2014). Number of selection and turnover differences were assessed qualitatively as follows: $<1 \%$, almost certainly not; $1-5 \%$, very unlikely; $5-25 \%$, probably not; 25-75\%, possibly; 75-97.5\%, likely; 97.5-99\%, very likely; $>99 \%$, almost certain (Hopkins, Marshall, Batterham, \& Hanin, 2009). Frequency of facing opponents were compared by $\chi 2$ test. The level of significance was set at $\mathrm{p}<0.05$.

\section{Results}

Selections trend

During the twentieth century (1906-2014), the number of games per year and the mean selections of players consequently increased: 1.3 selections for players in 1906 to 22.5 in 2014. Throughout this period, there was a trivial difference between the number of selections per player in winning teams and losing teams $19.6 \pm 18.7$ vs $16.3 \pm 18.0$ selections respectively (trivial, ES=0.18, possibly trivial, 70,6\%). Since 1987, players who have participated in the RWC, have a significantly higher number of selections than players who have participated in other international competitions (tournaments: 6 Nations, summer and autumn tournaments): $33 \pm 22.3$ vs $25.4 \pm 21.5$ selections respectively (small, $E S=0.35$, very likely positive, $95.3 \%$ ).

Turnover

The percentages of turnovers for forwards and backs, after victorious games are $33 \pm 26.4$ and $32.3 \pm 25 \%$ respectively, and are not significantly different after a lost game: $35.2 \pm 27.1$ and $35.1 \pm 26.5 \%$ respectively (the effect for forwards is trivial, $\mathrm{ES}=0.08$, likely trivial, $82.5 \%$ and the effect for backs is trivial, $\mathrm{ES}=0.11$, likely trivial, $76.6 \%$ ). By contrast, teams who lose 
have a significantly higher turnover rate. In winning teams only, the forwards' group changed by $29.8 \pm 26.9 \%$, whereas in losing teams, their counterparts underwent a change of $41.5 \pm$ $24.4 \%$ (Figure 1). In victorious teams only, the backs' group changed by $29.5 \pm 25.3 \%$, whereas in losing teams, their counterparts underwent a change of $40.8 \pm 24.7 \%$ (Figure 1 ) (for both forwards and backs, the effect is small, $\mathrm{ES}=0.45$, very likely positive, 98.5\%). Turnovers do not determine the outcome of a winning or losing team in previous games, but a higher turnover rate is associated with the loss of the game.

\section{Shared selections}

Figure 2 illustrates all shared selections by halfbacks, centres, and locks, and their respective victory percentage during the 1987-2014 period (left side). A common pattern between halfbacks, centres, and locks is revealed: whether the match was won or not, renewed couples contribute to the $X V$ de France's overall victory percentage (Figure 2). However "best vs rest" classification indicates that the majority of the "best" begins with a win, except for the ParaTrinh-Duc and Accoceberry-Deylaud halfbacks and Traille-Marty centres, which begin with one or two defeats. Over time, a convergence phenomenon allowed all recreated pairs to move toward the team's average winning percentage: $62.4 \%$ (for 1987-2014 period). In figure 2 , the right side indicates the best and rest reconstructed halfbacks, locks, and centres' opponents. There are no significant differences between opponent distributions from the Tri nations, VI nations or other teams, for the three recreated pairs in the best and rest groups. 
Overall selections

For every best recreated team, the number of selections for forwards is always higher than the rest of the team's: $223.6 \pm 91.3$ vs $213.3 \pm 100$ selections (the effect is trivial, $E S=0.11$, possibly trivial, $64.8 \%$ ) for forwards surrounding halfbacks, $240.6 \pm 96.3$ vs $229.9 \pm 81$ selections (the effect is trivial, $\mathrm{ES}=0.12$, possibly trivial, $70.8 \%$ ) for locks' teammates and $231.3 \pm 80 \mathrm{vs}$ $212.9 \pm 91$ selections (the effect is small, $\mathrm{ES}=0.22$, possibly positive, $54.8 \%$ ) for those playing with centres. Among the best teams, left loosehead props and eighthmen surround halfbacks with significantly more selections than those in less efficient teams, $23.1 \pm 18.8$ vs $17.7 \pm 14.1$ selections (the effect is small, ES=0.3, likely positive, $75.2 \%$ ) and $30 \pm 24.1$ vs $22.6 \pm 21.1$ selections (the effect is small, ES=0.3, likely positive, 76.3\%) respectively (Figure 3). Recreated locks among the best teams consist of a number 4 with more selections than locks in rest teams $(50.2 \pm 37.1$ vs $29.7 \pm 20$ selections, the effect is moderate, $E S=0.7$, most likely positive, 99.8\%). Best recreated locks are surrounded by blindside flankers, and eighthmen who add up a significantly higher number of selections than their counterparts in rest teams, $29.5 \pm 16.9$ vs $24.6 \pm 17.3$ selections (the effect is small, $\mathrm{ES}=0.3$, possibly positive, $74.2 \%$ ) and $32.3 \pm 26$ vs $26.1 \pm 21$ selections (the effect is small, $\mathrm{ES}=0.3$, possibly positive, $69.8 \%$ ) respectively ( (Figure 3). Centres in best teams are surrounded by higher selected number 4's ( $40.8 \pm 28.3$ vs $24.1 \pm 11.7$ selections, the effect is moderate, $\mathrm{ES}=0.6$, most likely positive, 99.6\%). In rest teams these players are surrounded by fly-halves, outside centres, and right wings with significantly more selections than their counterparts in best teams, $22.8 \pm 16.4 \mathrm{vs}$ $18.4 \pm 12.8$ selections (the effect is small, $\mathrm{ES}=0.3$, likely positive, $76.8 \%$ ), $56.7 \pm 35.1$ vs $24.1 \pm 19.7$ selections (the effect is large, $\mathrm{ES}=1.2$, likely positive, $90.8 \%$ ) and $22.2 \pm 18.4 \mathrm{vs}$ 16.1 \pm 11.9 selections (the effect is small, $\mathrm{ES}=0.4$, likely positive, $90.7 \%$ ) respectively. 


\section{Discussion}

To our knowledge the present study is the first to quantify the effect of an individual's selections number and shared selections on rugby union game results.

XV de France history

During the 1906-2014 period, the number of total players' selections in victorious teams is significantly greater than those in defeated teams. Head coaches select more experienced players to participate in RWC. Indeed, picking the "toughest" players on the international scene is coherent with a greater playing experience that correlates with better tackling technique (Gabbett \& Ryan, 2009) and skill (Smart et al., 2013).

\section{Turnovers and consequences}

Whether teams win or lose, head coaches change around 30\% of their workforce. The fact that they renew $70 \%$ of players is in accordance with studies, which found that a previous performance was a positive predictor of collective efficacy at the group level (Myers, Payment, \& Feltz, 2004; Watson, Chemers, \& Preiser, 2001). Nonetheless, teams who lose games have a significantly higher turnover rate: around $40 \%$ for all teams. These results underline the optimum rate of turnovers, which seems to depend on team size (Whitfield, 2008). Indeed, small groups draw benefit from some turnovers (Whitfield, 2008), but can only do so in stable conditions and line-up/composition remaining unchanged (Palla, Barabási, \& Vicsek, 2007). According to Whitfield, it is recommended to have a «healthy mix of rookies and veterans », which this study showed 70\% incumbents (Whitfield, 2008). 
These results are also consistent with previous results showing that collective experience of the forwards' pack increased with the final ranking (Sedeaud et al., 2012). These results express the relationship and trade-off between stability and turnovers.

\section{Recreated effectiveness}

Teams show more than the total of their individuals; they also exhibit the impact of players' experience hidden in the team performance; consequently sharing experience reveals a new kind of parameter. Such an indicator may evaluate the interactions among members, beyond the players individual characteristics (Bourbousson, Poizat, Saury, \& Seve, 2010). Over time, a convergence phenomenon for all recreated pairs emerges: when shared selections increase, the percentage of victories tends to increase as well: $62.4 \%$ (winning average for the study period of the $X V$ de France). Time is required for the construction of collective effectiveness, especially for the most exposed positions (halfback, centre, and locks). Indeed, this is also shown in top soccer teams that also display higher cohesion and collective efficacy (Leo et al., 2013). This kind of attribute is built primarily through shared selection. In rugby, identifying how quantitative measures of an individual's sharing game may impact team performance is crucial, as this sport requires both individual and collective work to win duels and contests. Moreover, effective interpersonal coordination is based on pre-shared elements and common organization (Lim \& Klein, 2006). These coordination dynamics are built with

time in order to coordinate implicitly, and create a mutual intelligibility of the game. The strategic common benchmarks (during static phase, movement or fixing) are also better acquired during training and reproduced during the game (such as to act and react according to teammates) in response to the opponents' moves. In team sports, it is fundamental to bring 
out individual and collective tactical intelligence, allowing for smooth and rapid switches from striker to defender. During this turnover state, it is imperative to create uncertainty among opponents, but still remain understandable to one's partners. These adjustments require a higher rate of games shared. When players break, their teammates need to be efficient at supporting them and making clean rucks to ensure continuity of progression. This kind of cohesion requires the creation of collective references and team ability to anticipate. Playing together for a long time appears to be the key point in bringing out these situational adaptations.

\section{Surrounding teammates}

Individual features such as personal selections are quantified to rebuild the kind of team that borders recreated dyads (halfbacks, centres, locks). Indeed, teams' composition is involved in their odds of success (Guimerà et al., 2005; Wuchty et al., 2007). For all best reconstructed teams, dyads are surrounded by higher selected forwards (particularly number 1 and 8 for halfbacks, numbers 4,6 , and 8 for locks and 4 for centres), like in RWC teams, which the percentage of forwards participating at the previous RWC increased with the final ranking attained (Sedeaud et al., 2012). Collective effectiveness combines not only physical and tactical individual skills, but also a strong complicity, acquired over the years. Collectively adapting to opponents' attacks and providing a common effort, requires a shared knowledge and a combined action, especially for forwards. These collective investments are the forwards' cornerstone actions, such as providing support in breakdowns, synchronisation during line-outs, maul for placement, collective push, and orientation in scrums (Sedeaud et al., 2012). Best vs Rest analyses do not show significant differences in opponents: best teams are not better because they play less successful teams. Moreover, numbers 4, 6, and, 8 which 
surround the locks, have the highest number of selections. This result is consistent with the fact that these teammates permanently interact and provide common effort either on offence or defence or during breakdown. Eighthmen and openside flankers are not only the first forwards in a breakdown to secure the ball, but are also good at reading the opposition's attacking lines, a task that requires strong coordination with their teammates and experience. Centres with the lowest winning percentages play on teams with the numbers 10,13 , and 14, who have a higher number of selections. This result also questions the backs' role specificity and qualities: speed, change of direction, agility, high handling skills, with line break, off-loads pass, and outflanking capabilities. Indeed, speed and change of direction capacities require athletes of a younger age (Berthelot et al., 2012). Surrounding teammates' selections underline the fact that a team of experts is not necessarily an expert team (Bourbousson et al., 2010; Eccles, et al., 2004). Teams require coordination that rely on shared knowledge and action (Eccles et al., 2004).

This study establishes an indicator of Pierre Villepreux's thoughts: «The reality of rugby is not managing an isolated player but the optimal management of a complex system in which it operates » (Villepreux, 1993).

Perspectives

Similar to Duch et al, who provided an objective quantification of individual and team performance (Duch et al., 2010), this study provides an indicator of playing together through shared and surrounded selection of a rugby union team. This is the first step toward a relevant and systemic indicator of personal and collective experience, which are both connected through dyads. To develop such a complete set of indicators, it will be necessary to measure 
all team members' shared selections (including substitutes) and incorporate game actions (pass, try, penalty, tackle...). Network dynamics is another scope to explore and apply to team construction. Finally, quantifying selections primarily underline the head coach's choices rather than collective building. Questions to be studied will address how and how long the process of building collective effectiveness develops.

\section{Conclusion}

This study is the first to quantify the effect of selections number and shared selections on rugby union game results. The $X V$ de France's collective effectiveness relies on a balance between stability and turnovers. Time is required for building interactions within specific positions such as halfbacks. Moreover, the best halfbacks, locks, and centres are surrounded by more experimented forwards. The number of shared selections is an important quantifiable parameter to access collective effectiveness and impact collective performance.

\section{Acknowledgements}

The authors wish to thank INSEP teams for their full support. The authors thank Scott Del Vecchio for proofreading the manuscript and providing valuable critique and advice. The results of the current study do not constitute endorsement of the product by the authors or the journal. 


\section{References}

Batterham, A. M., \& Hopkins, W. G. (2006). Making meaningful inferences about magnitudes. International Journal of Sports Physiology and Performance, 1(1), 50-57.

Berthelot, G., Len, S., Hellard, P., Tafflet, M., Guillaume, M., Vollmer, J.-C., ... Toussaint, J.-F. (2012). Exponential growth combined with exponential decline explains lifetime performance evolution in individual and human species. Age (Dordrecht, Netherlands), 34(4), 1001-1009. http://doi.org/10.1007/s11357-011-9274-9

Bourbousson, J., Poizat, G., Saury, J., \& Seve, C. (2010). Team coordination in basketball: Description of the cognitive connections among teammates. Journal of Applied Sport Psychology, 22(2), 150-166.

Cunniffe, B., Proctor, W., Baker, J. S., \& Davies, B. (2009). An evaluation of the physiological demands of elite rugby union using Global Positioning System tracking software. Journal of Strength and Conditioning Research / National Strength \& Conditioning Association, 23(4), 1195-1203. http://doi.org/10.1519/JSC.0b013e3181a3928b

Duch, J., Waitzman, J. S., \& Amaral, L. A. N. (2010). Quantifying the performance of individual players in a team activity. PloS One, 5(6), e10937. http://doi.org/10.1371/journal.pone.0010937

Eaves S., \& Hughes M. (2003). Patterns of play of international rugby union teams before and after the introduction of professional status. International Journal of Performance Analysis in Sport, 3 , 103-111.

Eccles, D. W., Tenenbaum, G., \& others. (2004). Why an expert team is more than a team of experts: A social-cognitive conceptualization of team coordination and communication in sport. Journal of Sport and Exercise Psychology, 26(4), 542-560.

Fransen, K., Decroos, S., Vanbeselaere, N., Vande Broek, G., De Cuyper, B., Vanroy, J., \& Boen, F. (2014). Is team confidence the key to success? The reciprocal relation between collective efficacy, team outcome confidence, and perceptions of team performance during soccer games. Journal of Sports Sciences, 1-13. http://doi.org/10.1080/02640414.2014.942689

Gabbett, T. J. (2005). Science of rugby league football: a review. Journal of Sports Sciences, 23(9), 961-976. http://doi.org/10.1080/02640410400023381

Gabbett, T. J. (2008). Influence of fatigue on tackling technique in rugby league players. Journal of Strength and Conditioning Research / National Strength \& Conditioning Association, 22(2), 625-632. http://doi.org/10.1519/JSC.0b013e3181635a6a

Gabbett, T., \& Ryan, P. (2009). Tackling technique, injury risk, and playing performance in highperformance collision sport athletes. International Journal of Sports Science and Coaching, 4(4), 521533. 
Guimerà, R., Uzzi, B., Spiro, J., \& Amaral, L. A. N. (2005). Team assembly mechanisms determine collaboration network structure and team performance. Science (New York, N.Y.), 308(5722), 697702. http://doi.org/10.1126/science. 1106340

Heuzé, J.-P., Raimbault, N., \& Fontayne, P. (2006). Relationships between cohesion, collective efficacy and performance in professional basketball teams: an examination of mediating effects. Journal of Sports Sciences, 24(1), 59-68. http://doi.org/10.1080/02640410500127736

Hopkins, W. G., Marshall, S. W., Batterham, A. M., \& Hanin, J. (2009). Progressive statistics for studies in sports medicine and exercise science. Medicine and Science in Sports and Exercise, 41(1), 3-13. http://doi.org/10.1249/MSS.0b013e31818cb278

Kozub, S., \& McDonnell, J. (2000). Exploring the relationship between cohesion and collective efficacy in rugby teams. Journal of Sport Behaviour, 23(2), 120-129.

Lacome, M., Piscione, J., Hager, J.-P., \& Bourdin, M. (2014). A new approach to quantifying physical demand in rugby union. Journal of Sports Sciences, 32(3), 290-300.

http://doi.org/10.1080/02640414.2013.823225

Leo, F. M., Sanchez-Miguel, P. A., Sanchez-Oliva, D., Amado, D., \& Garcia-Calvo, T. (2013). Analysis of Cohesion and Collective Efficacy Profiles for the Performance of Soccer Players. Journal of Human Kinetics, 39, 221-229. http://doi.org/10.2478/hukin-2013-0085

Lim, B.-C., \& Klein, K. J. (2006). Team mental models and team performance: a field study of the effects of team mental model similarity and accuracy. Journal of Organizational Behavior, 27(4), 403418.

Mellalieu, S., Trewartha, G., \& Stokes, K. (2008). Science and rugby union. Journal of Sports Sciences, 26(8), 791-794. http://doi.org/10.1080/02640410701819099

Myers, N. D., Payment, C. A., \& Feltz, D. L. (2004). Reciprocal Relationships Between Collective Efficacy and Team Performance in Women's Ice Hockey. Group Dynamics: Theory, Research, and Practice, 8(3), 182.

Palla, G., Barabási, A.-L., \& Vicsek, T. (2007). Quantifying social group evolution. Nature, 446(7136), 664-667. http://doi.org/10.1038/nature05670

Quarrie, K. L., \& Hopkins, W. G. (2007). Changes in player characteristics and match activities in Bledisloe Cup rugby union from 1972 to 2004. Journal of Sports Sciences, 25(8), 895-903. http://doi.org/10.1080/02640410600944659

Sedeaud, A., Marc, A., Schipman, J., Tafflet, M., Hager, J.-P., \& Toussaint, J.-F. (2012). How they won Rugby World Cup through height, mass and collective experience. British Journal of Sports Medicine, 46(8), 580-584. http://doi.org/10.1136/bjsports-2011-090506

Smart, D. J., Hopkins, W. G., \& Gill, N. D. (2013). Differences and changes in the physical characteristics of professional and amateur rugby union players. The Journal of Strength \& 
Conditioning Research. Retrieved from http://pdfs.journals.Iww.com/nscajscr/9000/00000/Differences_and_changes_in_the_physical.97782.pdf

Stajkovic, A. D., Lee, D., \& Nyberg, A. J. (2009). Collective efficacy, group potency, and group performance: meta-analyses of their relationships, and test of a mediation model. The Journal of Applied Psychology, 94(3), 814-828. http://doi.org/10.1037/a0015659

Villepreux, P. (1993). Formation au rugby de mouvement. Editions Cépaduès.

Walsh, M., Young, B., Hill, B., Kittredge, K., \& Horn, T. (2007). The effect of ball-carrying technique and experience on sprinting in rugby union. Journal of Sports Sciences, 25(2), 185-192.

http://doi.org/10.1080/02640410600630571

Watson, C. B., Chemers, M. M., \& Preiser, N. (2001). Collective efficacy: A multilevel analysis. Personality and Social Psychology Bulletin, 27(8), 1057-1068.

Whitfield, J. (2008). Collaboration: Group theory. Nature, 455(7214), 720-723. http://doi.org/10.1038/455720a

Winter, E. M., Abt, G. A., \& Nevill, A. M. (2014). Metrics of meaningfulness as opposed to sleights of significance. Journal of Sports Sciences, 32(10), 901-902.

http://doi.org/10.1080/02640414.2014.895118

Wuchty, S., Jones, B. F., \& Uzzi, B. (2007). The increasing dominance of teams in production of knowledge. Science (New York, N.Y.), 316(5827), 1036-1039.

http://doi.org/10.1126/science.1136099. 
Forwards

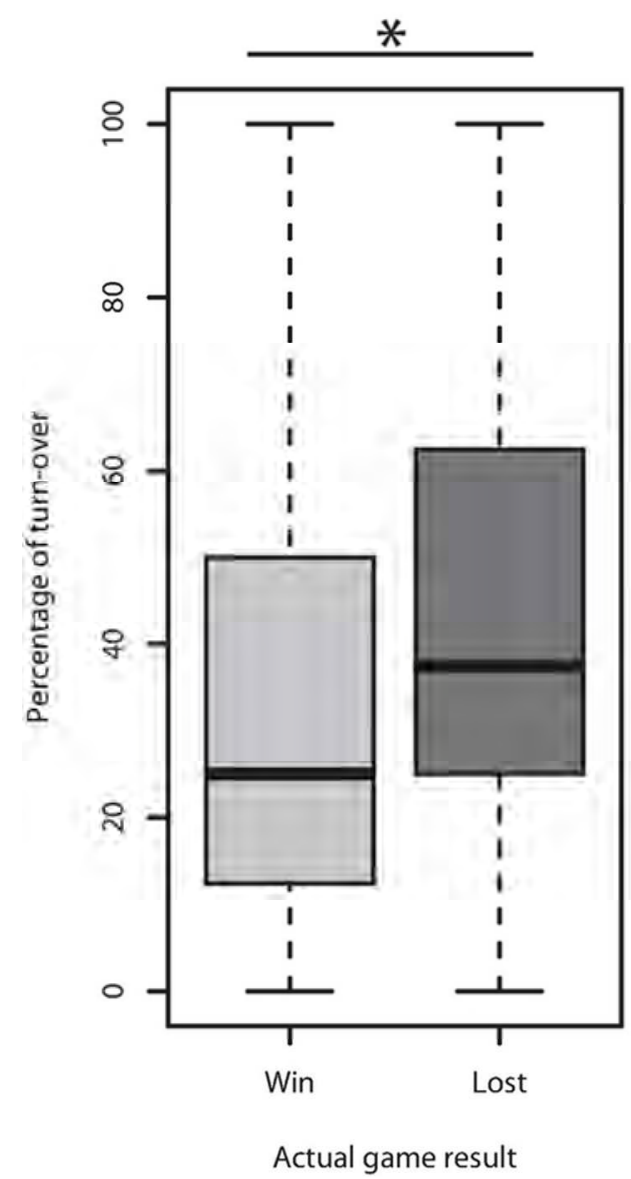

Backs

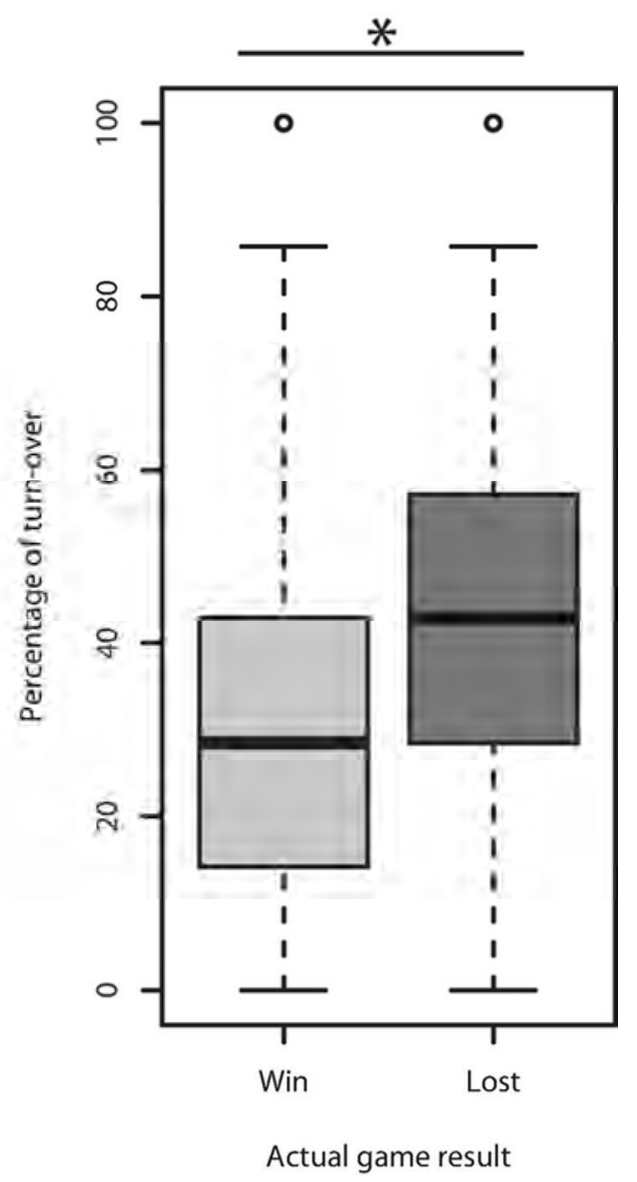

Percentage of turnovers for forwards and backs based on the actual game result. ${ }^{*} p<0.05$ between game results.

$77 \times 74 \mathrm{~mm}(300 \times 300$ DPI $)$ 

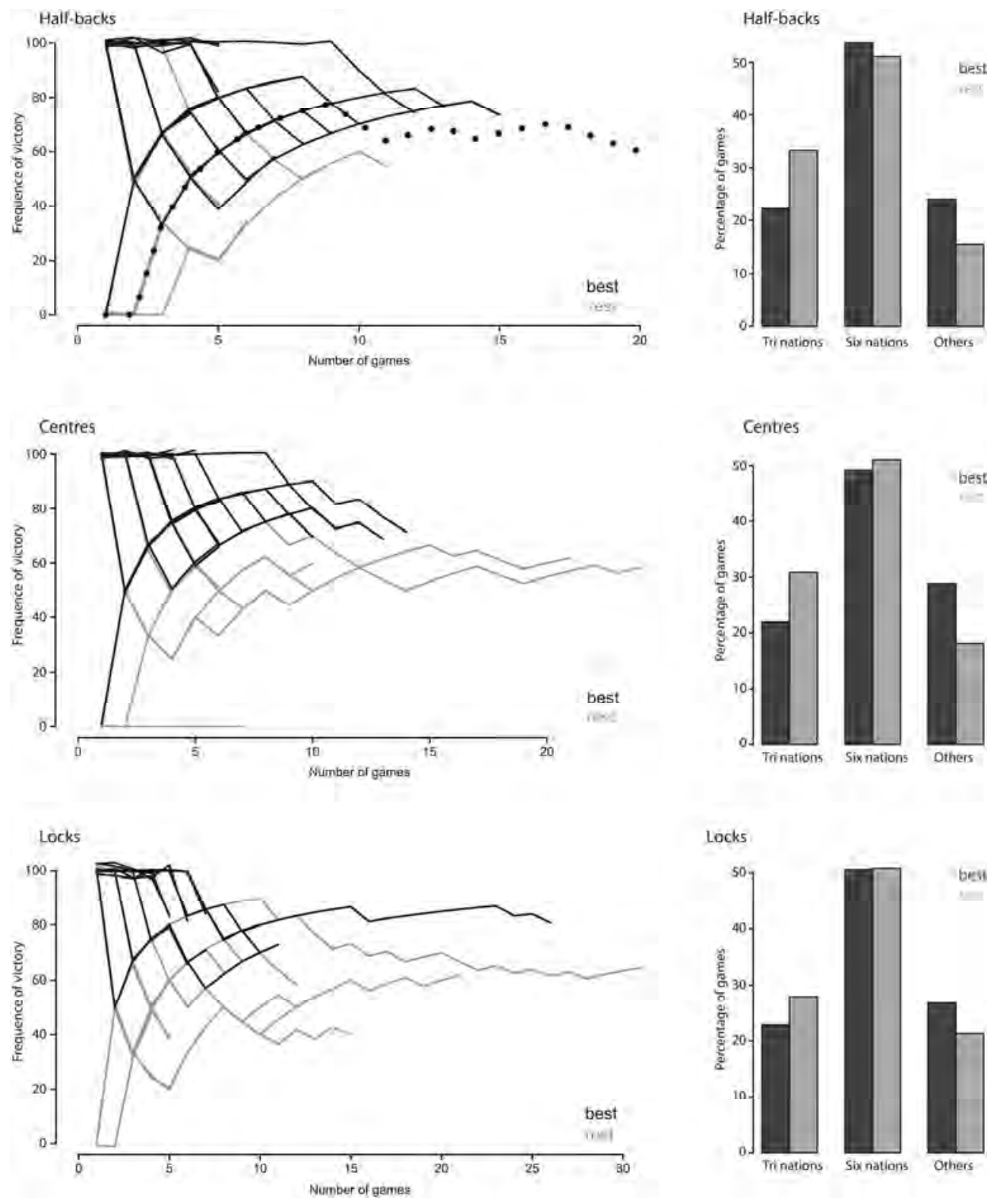

To the left: the frequency of victory changes based on shared selection of halfbacks, centres and locks. For example the halfbacks' figure expresses in a dotted line the recreated Para-Trinh-Duc association, which began with two defeats (the first two points at $0 \%$ of frequency of victory) and followed with seven wins. Each line corresponds to a recreated association for one dyad of a halfback, centre and lock during the 1987-2014 period. To the right: the percentage of games played against Tri Nations teams (New Zealand, South Africa and Australia), Six Nations teams (England, Ireland, Wales, Scotland and Italy) and others squads of the best and rest recreated association (for best and rest halfbacks, centres and locks from the top of the figure downwards). 

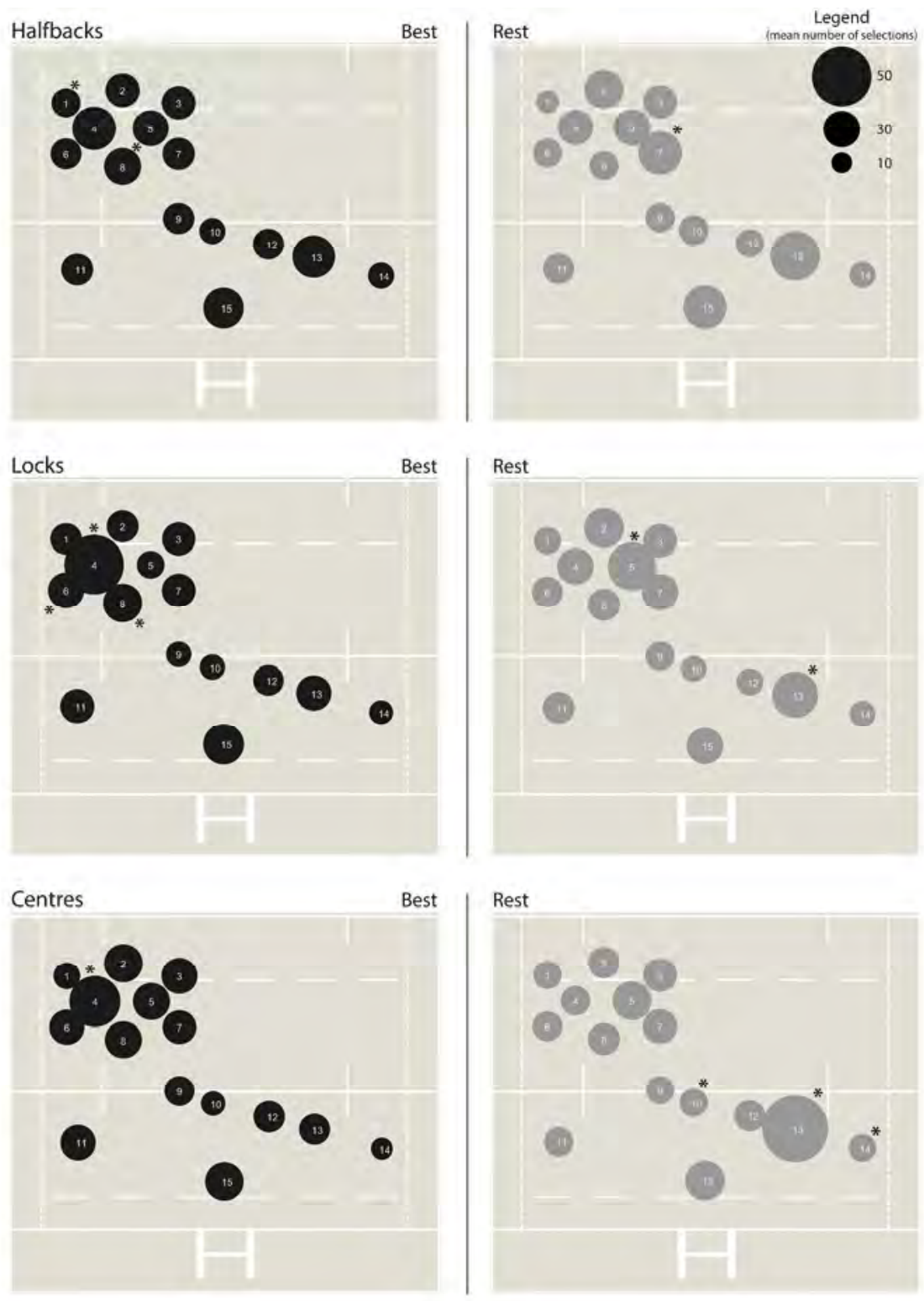

The comparison of players' selections by position surrounded recreated halfbacks, locks and centres pairs in best and rest teams. ${ }^{*} p<0.05$ between best and rest team players of the same position. Circle diameters depict the number of mean selections by position. Their Positions and respective numbers are depicted as a standard rugby union team organization. 